\title{
KLUB OLAHRAGA DI KAWASAN KAPUK, JAKARTA
}

\author{
Edmund $^{1)}$ \\ 1)Program Studi S1 Arsitektur, Fakultas Teknik, Universitas Tarumanagara, benedictus_110997@yahoo.com
}

\begin{abstract}
Abstrak
Jakarta merupakan kota besar yang memiliki jumlah penduduk sebesar 10.374.235 jiwa dengan luas wilayah $661.52 \mathrm{~km}^{2}$, hal ini menunjukkan bahwa kota Jakarta merupakan daerah yang sangat padat akan penduduknya di Indonesia. Sebagai Ibukota dan sebagai kota besar pasti memiliki kepadatan akan aktivitas rutin yang dapat menimbulkan kejenuhan dan menekan mental masyarakat yang tinggal maupun yang datang untuk bekerja. Hal-hal tersebut perlu menjadi perhatian pemerintah. Untuk mengatasi permasalahan tersebut, diperlukan adanya sebuah tempat yang dapat mewadahi masyarakat untuk beristirahat, berkomunikasi, dan menghibur diri dari kesibukan yang menjadi aktivitas utama masyarakat di kota besar yang disebut sebagai the third place. Dengan keterbatasan waktu dan kemajuan teknologi, masyarakat menjadi bermalasmalasan untuk berinteraksi dan berolahraga. Isu mengenai kurangnya fasilitas olahraga di wilayah Jakarta juga menjadi perhatian pemerintah Jakarta. Dewan Perwakilan Rakyat Daerah (DPRD) menyoroti kurangnya sarana dan prasarana olahraga di Jakarta. Masyarakat Indonesia yang menyadari pentingnya berolahraga dan menjalaninya hanya sebesar $27.61 \%$, angka tersebut merupakan angka yang cukup rendah dibandingkan dengan negara lain. Melalui pendekatan tipologi untuk kegunaan ruang dan dipadukan dengan metode konvensional, desain dapat memberikan kegunaan ruang secara baik untuk masyarakat. Dengan menghadirkan sebuah wadah sarana olahraga baru yang di gabungkan dengan konsep third place diharapkan dapat menyadarkan masyarakat akan pentingnya berinteraksi, berolahraga dan menjaga kesehatan fisik maupun non fisik.
\end{abstract}

Kata kunci: fasilitas olahraga; Jakarta; kepadatan aktivitas; olahraga; third place

\begin{abstract}
Jakarta is a large city that has a population of 10,374,235 people on $661.52 \mathrm{~km}^{2}$ land, which shows that Jakarta is a very densely populated area in Indonesia. As the capital and as a big city, it certainly has a density of routine activities that can lead to boredom and suppress the mentality of the people who live or come to work. These things should become the attention of the government.To overcome these problems, it is necessary to have a place that can facilitate the community to rest, communicate, and entertain themselves from the busyness that is the main activity of the people in the big cities, called as the third place. With limited time and technological advances, people become lazy to interact and exercise. The issue of the lack of sports facilities in the Jakarta area is also a concern for the Jakarta government. The Regional Representative Council (DPRD) highlighted the lack of sports facilities and infrastructure in Jakarta. People in Indonesia who realize the importance of exercising and doing it are only $27.61 \%$, this figure is a fairly low number compared to that in other countries. With a typology approach to use of space and combined with conventional methods, design can provide good use of space for the community. By creating a new container for sports facilities combined with the concept of third place, it is expected that people can be aware of the importance of interacting, exercising and maintaining physical and non-physical health.
\end{abstract}

Keywords: activity density; Jakarta; sports facility; sports; third place 


\section{PENDAHULUAN}

Jakarta merupakan kota besar yang memiliki jumlah penduduk sebesar 10.374.235 jiwa dengan luas wilayah $661.52 \mathrm{~km}^{2}$ (Badan Pusat Statistik Jakarta, 2017), hal ini menunjukkan bahwa kota Jakarta merupakan daerah yang sangat padat penduduk di Indonesia. Sebagai Ibukota dan sebagai kota besar pasti memiliki kepadatan dan aktivitas rutin yang dapat menimbulkan kejenuhan dan menekan mental masyarakat yang tinggal maupun yang datang untuk bekerja. Masyarakat di kota Jakarta akan semakin sibuk karena persaingan di zaman sekarang yang semakin tinggi terutama dengan masalah ekonomi dan teknologi yang sudah maju. Kesibukan yang secara tidak langsung ini yang menjadi permasalahan kepada kondisi kesehatan baik secara fisik (kesehatan tubuh atau kebugaran) maupun non fisik (stress, mental yang kurang stabil, dan emosional). Hal itu juga membuat seseorang menjadi kurang berkomunikasi dengan orang lain atau orang asing sehingga menimbulkan sifat yang individualistik.

Hal-hal tersebut pula menjadi perhatian pemerintah. Untuk mengatasi permasalahan tersebut di perlukan adanya sebuah tempat yang dapat mewadahi masyarakat untuk beristirahat, berkomunikasi, dan menghibur diri dari kesibukan yang menjadi aktivitas utama masyarakat di kota besar yang disebut sebagai The Third place. The Third place merupakan suatu wadah atau tempat atau program yang mengakomodasikan masyarakat di kota-kota besar agar dapat menjadi masyarakat yang humanis, terbuka, dinamis, dan produktif. Faktor kesibukan inilah yang sering menyebabkan masyarakat terkena tekanan mental terutama stress, yang dapat mengundang berbagai penyakit (obesitas, sakit punggung, gangguan pencernaan, diabetes, penyakit jantung, penyakit kulit, dan lain-lain). Dengan adanya kemajuan teknologi saat ini juga masyarakat menjadi individualis sehingga jarang masyarakat yang berkomunikasi secara langsung dengan orang lain dan juga membuat seseorang menjadi malas untuk bergerak. Mereka lebih sering mencari hiburan di dalam rumah saja dibandingkan berinteraksi dan berkomunikasi di luar atau berkomunikasi pada saat bekerja di tempat kerja saja. Hal ini juga membuat masyarakat menyukai akan hal-hal yang praktis atau serba cepat, misalnya memakan makanan cepat saji karena harga yang terjangkau dan cepat, sedangkan makanan tersebut belum tentu baik dan sehat bagi tubuh. Dengan kepadatan yang tinggi, masyarakat menjadi malas untuk berolahraga karena masalah lingkungan yang kurang mendukung dan infrastruktur fasilitas yang kurang memadai.

Berdasarkan data dari artikel Suara, 3 Oktober 2018, masyarakat yang menyadari pentingnya berolahraga dan menjalaninya hanya sebesar 27,61\% (2015) dari 270.054.853 juta jiwa yang tinggal di Indonesia ini termasuk kota Jakarta. Angka tersebut merupakan angka yang sangat rendah dibandingkan dengan negara lain. Tingkat kesehatan mental pada masyarakat Jakarta juga cukup tinggi. Menurut Kompas, 30 Oktober 2017, Jakarta merupakan kota paling stress di dunia yang berada pada urutan ke-18 dari 150 kota yang diteliti oleh perusahaan jasa penatu Zipjet dengan skor 7,84 dari angka 1-10. Hal ini menunjukkan bahwa kota Jakarta memiliki masalah kesehatan dan kebugaran yang sangat memprihatinkan. Kurangnya fasilitas atau sarana kebugaran pada kawasan juga menjadi kendala untuk menjaga kebugaran dan kesehatan masyarakat. Menurut Berita Satu, 13 November 2015, Dewan Perwakilan Rakyat Daerah (DPRD) DKI menyoroti kurangnya sarana dan prasarana olahraga di Jakarta. DPRD DKI menilai pemprov DKI kurang serius dalam meningkatkan kualitas sarana dan prasarana olahraga di Ibu Kota. Hal itu terlihat dari minimnya pembangunan sarana dan prasarana olahraga di tingkat RT/RW hingga Kotamadya.

Untuk mencegah kemungkinan-kemungkinan yang menjadikan kualitas hidup yang kurang baik, manusia membutuhkan pola hidup yang sehat dan melakukan rutinitas olahraga. Pada zaman modern saat ini masyarakat di kota besar sangat jarang melakukan kegiatan olahraga terutama di kota Jakarta, karena infrastruktur yang kurang memadai dan juga keadaan lingkungan yang kurang mendukung menjadikan masyarakat tidak bersemangat untuk menjalankan kegiatan olahraga secara rutin. Dengan jumlah penduduk yang banyak dan padat di perlukan tempat atau wadah untuk berolahraga yang cukup. 


\section{KAJIAN LITERATUR}

\section{Open Architecture}

Open architecture merupakan sistem terbuka yang berfungsi sebagai ruang antara bukan sebagai tempat untuk tinggal (home) dan tempat untuk bekerja (work). Permasalahan pada kota-kota besar biasanya memiliki ciri masyarakat yang individualistis dan lebih sensitif dengan personal space-nya. Maka dari itu open architecture tidak dapat dilihat dari masalah arsitekturnya saja tetapi masalah sosial yang ada pada kota-kota tersebut. Terdapat aspek-aspek yang mengarah kepada open architecture yaitu open society dan open city. Open society adalah sekelompok masyarakat yang memiliki toleransi dan keterbukaan, open city merupakan jawaban dari open society dalam bentuk fisik ruang dengan membangun sebuah kota secara bersama-sama dengan menggunakan open system (sistem yang terbuka secara sosial). Open system mendukung dan merangkul karakter kota menjadi adaptif dan eksperimental. Open architecture sendiri juga didasarkan pada penyambutan dari sepemikiran atau berbagai pemikiran lain yang jelas ke dalam proses desain arsitektur. Open architecture juga dikaitkan dengan, misalnya fleksibilitas dan kemampuan beradaptasi bentuk, kolektivitas dan kolaborasi, multiplisitas makna, demokrasi dan pluralitas, desain yang terbuka, perluasan hak asasi manusia dan kewarganegaraan sosial, dan solidaritas transnasional. (Akcan, 1984)

\section{The Third place}

Open architecture merupakan the third place bagi masyarakat kota. The third place adalah sebuah program yang akan membantu masyarakat kota agar bersifat humanis, open, dan dinamis. Membantu masyarakat untuk memahami kota sebagai entitas bersama dengan layanan publik bersama, sumber daya infrastruktur bersama, dan ruang bersama (McLaren \& Agyeman, 2015). Kemunculan third place sendiri disebabkan dari faktor revolusi Industri, dimana tempat bekerja dan tempat tinggal berada di tempat yang berbeda (Oldenburg, 1997).

Letak permukiman dibuat terpisah jauh dari pusat kota, sehingga memaksa mobilitas yang tinggi. Lingkungan yang dahulu memiliki tempat untuk bersosialisasi di tengah permukiman seperti kafe atau bar menghilang keberadaanya. Hal ini membuat individu di dalamnya hanya memiliki kesempatan kecil untuk merasa saling terkait dalam sebuah hubungan sosial dengan sekitarnya. The third place menurut Oldenburg (1997) memiliki kriteria-kriteria sebagai berikut:

a. Mereka Neutral (tidak membedakan)

Setiap individu dapat datang dan pergi sesuai keinginannya, mereka tidak terikat pada third place secara finansial, politik, hukum, atau lainnya.

b. Kesejajaran dalam bermasyarakat (Leveler)

Third place tidak mementingkan status ekonomi atau sosial seseorang dalam suatu masyarakat. Tidak ada syarat atau hirearki sosial untuk berpartisipasi di dalam Third place.

c. Komunikasi menjadi hal penting dalam aktivitasnya

Percakapan yang menyenangkan adalah focus utama dari kegiatan Third place.

d. Mudah diakses dan mudah mengakomodasi

Third place harus terbuka, mudah diakses, dan akomodatif (memenuhi kebutuhan).

e. Mempunyai regulasi

Third place memiliki pengunjung tetap, hal ini memberikan atmosfir dalam ruang dan membantu interaksi sosial.

f. Third places secara fisik sederhana dan bersahaja

Bentuk third place terlihat sederhana, untuk menguatkan kesan kesetaraan bagi pengunjung yang datang dengan penampilan apa adanya.

g. Memiliki suasana yang playful (menyenangkan)

Percakapan di dalam third place bersifat menyenangkan, canda dan tawa lebih umum terdengar menjadi daya tarik third place di lingkungan sosial.

h. A Home Away From Home

Pengunjung memiliki rasa nyaman dan hangat tanpa ada kepemilikan bangunan pada third place. 


\section{Definisi Proyek}

Menurut Kamus Besar Bahasa Indonesia (KBBI, 2016), arti kata olahraga merupakan gerak badan untuk menguatkan dan menyehatkan tubuh (seperti sepak bola, berenang, lempar lembing, dan lain-lain). Olahraga adalah suatu proses aktivitas gerak yang didesain untuk meningkatkan kebugaran jasmani, mengembangkan keterampilan gerak, pengetahuan dan perilaku hidup sehat dan aktif, sikap sportif, dan kecerdasan emosi.

Untuk arti kata klub, menurut Kamus Besar Bahasa Indonesia (KBBI, 2016), arti kata club atau klub merupakan bagian perkumpulan yang kegiatannya mengadakan persekutuan untuk maksud tertentu. Menurut Kamus besar Bahasa Indonesia (KBBI, 2016), sport club atau klub olahraga dapat diartikan sebagai wadah atau suatu pangkal atau suatu tempat yang dijadikan sebagai tempat perkumpulan yang menyelenggarakan kegiatan dalam bidang olahraga.

\section{Jenis-jenis bangunan olahraga}

Menurut Buku Standar Tata Cara Perencanaan Teknik Bangunan Gedung Olahraga yang dikeluarkan oleh Departemen Pekerjaan Umum tahun 1994, Gelanggang Olahraga dibagi menjadi 3 tipe, yaitu :

a. Gelanggang Olahraga Tipe A adalah Gelanggang Olahraga yang dalam penggunaannya melayani wilayah Propinsi / Daerah Tingkat I.

b. Gelanggang Olahraga Tipe B adalah Gelanggang Olahraga yang dalam penggunaannya melayani wilayah Kabupaten / Kotamadya.

c. Gelanggang Olahraga Tipe C adalah Gelanggang Olahraga yang dalam penggunaanya melayani wilayah Kecamatan

Pusat olahraga (sport center) golongan $\mathrm{C}$ dapat digolongkan menjadi 2 golongan berdasarkan batasan pengguna atau kapasitas pengguna yang diperbolehkan menggunakan sarana ini, yaitu :

- Sports center milik suatu komplek hunian

Pada sports center semacam ini yang bisa menikmati fasilitas dan sarana di dalam Sports Center ini hanyalah penghuni atau pemilik dari hunian baik itu berupa rumah atau apartment atau penthouse itu saja. Hal ini membuat keterbatasan atau bahkan ketidakmampuan sport center seperti ini untuk bisa memberikan manfaat bagi masyarakat atau warga lain yang bukan merupakan penghuni komplek hunian tersebut.

- Sports center untuk umum

Sports center golongan umum ini yaitu pusat olahraga yang dapat digunakan atau dinikmati oleh semua kalangan atau semua orang yang ingin menjadi bagian atau ikut dalam kegiatan olahraga di dalam fasilitas sports center tersebut.

\section{Sejarah dan Perkembangan Bangunan Olahraga}

Klub yang bergerak di bidang kebugaran pertama kali muncul pada pertengahan abad ke-20 di Amerika. Awalnya klub ini berfungsi sebagai sarana olahraga yang di dalamnya hanya terdapat alat-alat olahraga untuk para binaraga. Konsumennya merupakan kaum pekerja dari kalangan kelas menengah ke bawah, yang dikenal dengan olahraga kaum blue collar, kemudian klub semacam ini terus berkembang hingga berbagai lapisan masyarakat. Perkembangan ini semakin pesat terlebih setelah terjadinya revolusi Perancis di Amerika (Sturzebecher \& Ulrich, 2002).

Pada pertengahan abad ke-20, tepatnya pada tahun 1962, sports club mulai masuk ke Indonesia. Pertama kali hadir di bumi Sangkuriang, Bandung yang diberi nama Country Club Concordia, kemudian diusul hadirnya Sawangan Country Club di daerah Sawangan, Bogor pada tahun 1970 yang berupa lapangan olahraga dengan kolam renang. Pada akhir abad ke-20, pendirian sports club ini semakin berkembang sesuai dengan perkembangan pemukiman. Program pada sports club juga bertambah dengan adanya kolam renang, lapangan olahraga, gym, senam, dan program hiburan seperti karaoke dan spa. Sports center ini menjadi fasilitas pelengkap yang disediakan oleh pengembang. 


\section{Jenis-jenis olahraga pada bangunan olahraga}

Terdapat 2 jenis olahraga yang terdapat pada Sports Center, antara lain (Kementerian Pendidikan dan Kebudayaan, 2017) :

a. Olahraga prestasi: kegiatan olahraga yang dilakukan dan dikelola secara profesional dengan tujuan untuk memperoleh prestasi optimal pada cabang-cabang olahraga. Jenis-jenis olahraga prestasi, antara lain:

a) Sepak Bola

Sepak bola adalah permainan bola yang dimainkan oleh dua regu, yang masing-masing beranggotakan sebelas orang. Tujuannya adalah memasukkan bola ke gawang lawan, dengan memanipulasi bola dengan kaki. Lapangan yang diperuntukkan bagi prasarana olahraga sepak bola berukuran $110 \mathrm{~m} \times 70 \mathrm{~m}$.

b) Futsal

Futsal adalah permainan bola yang dimainkan oleh dua regu, yang masing-masing regu memiliki anggota lima orang. Tujuannya sama seperti sepak bola tetapi ukuran lapangan lebih kecil di bandingkan dengan ukuran lapangan sepak bola yaitu 25-42 m x 15-25 m dengan lantai datar.

c) Bola Basket

Bola basket adalah olahraga berkelompok yang terdiri dari atas dua tim yang beranggotakan masing-masing lima orang yang saling bertanding mencetak poin dengan memasukkan bola ke dalam keranjang lawan. Prasarana olahraga yang diperuntukkan bagi permainan bola basket dengan ukuran lapangan sebesar $28 \mathrm{~m} \times 15 \mathrm{~m}$ dengan lantai terbuat dari beton atau vynil.

d) Bola Voli

Bola voli merupakan olahraga berkelompok yang terdiri dari atas dua grup berlawanan. Masing-masing grup memiliki enam orang pemain. Terdapat pula variasi permainan bola voli pantai yang masing-masing grup memiliki tiga orang pemain. Prasarana olahraga yang diperuntukkan bagi permainan bola voli dengan ukuran lapangan $18 \mathrm{~m} \times 9 \mathrm{~m}$ dengan lantai dari beton / tanah.

\section{e) Bulu Tangkis}

Bulu tangkis merupakan olahraga yang biasanya dimainkan antar dua individu pemain atau antara dua pasangan grup yang masing-masing memiliki dua orang pemain. Secara sederhana, permainan bulutangkis adalah upaya memasukkan kok ke bidang permainan lawan, sehingga tidak dapat dikembalikan. Ada berbagai cara melakukannya, seperti memasukkan kok ke bidang yang tidak terjaga lawan, atau memasukkan kok dengan cepat, sehingga tidak sempat dikuasai atau dikejar oleh lawan. Prasarana olahraga yang diperuntukkan bagi permainan bulu tangkis dengan ukuran lapangan 14,40 m x 6,10 m dengan lantai terbuat dari beton.

f) Tennis

Tennis merupakan olahraga yang biasanya dimainkan antara dua individu atau dua grup yang masing-masing grup memiliki dua orang pemain. Setiap pemain menggunakan raket untuk memukul bola karet. Tujuan permainan adalah memainkan bola dengan cara tertentu sehingga pemain lawan tidak dapat mengembalikan bola tersebut. Prasarana olahraga yang diperuntukkan bagi olahraga tennis lapangan dengan ukuran $23,77 \mathrm{~m} \times 10,97 \mathrm{~m}$. 


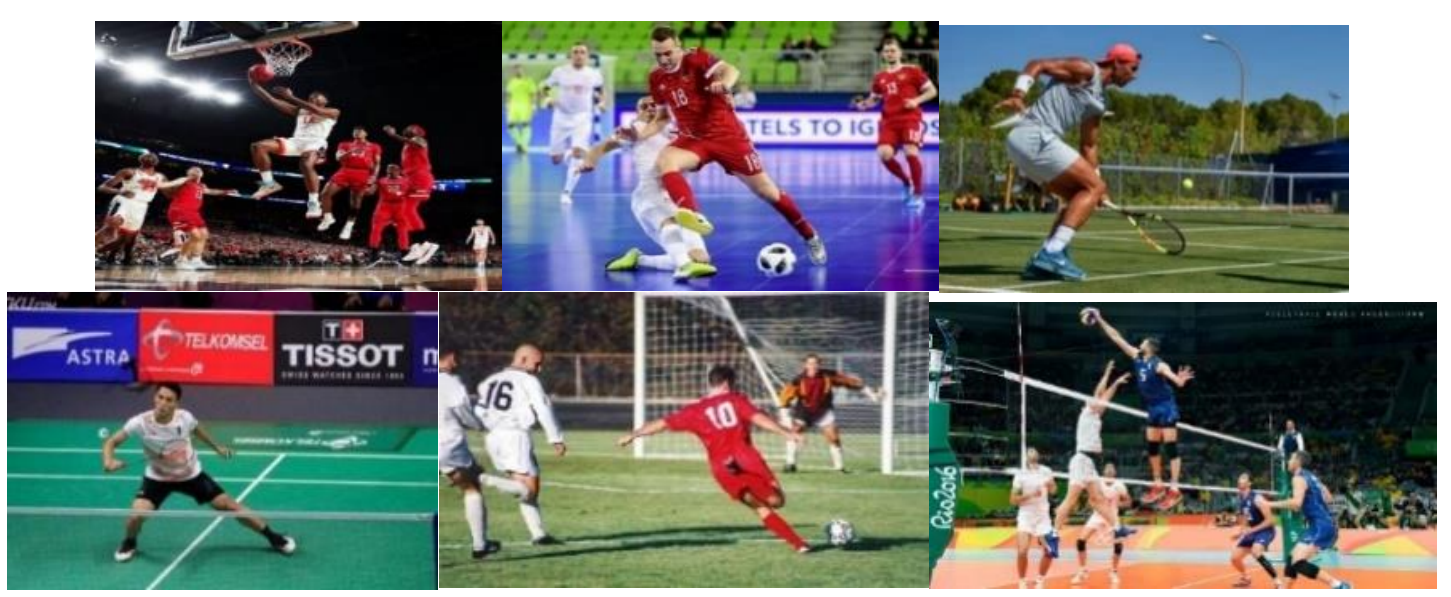

Gambar 1. Jenis-jenis Olahraga Prestasi

Sumber: Google, 2019

b. Olahraga rekreasi: kegiatan fisik yang dilakukan pada waktu senggang berdasarkan kehendak yang timbul karena memberi kepuasan atau kesenangan. Jenis olahraga rekreasi, antara lain:

a) Renang

Merupakan gerakan sewaktu bergerak di dalam air, kegiatan ini dapat dimanfaatkan untuk rekreasi dan olahraga dan bisa dilakukan tanpa menggunakan alat apapun. Berenang dipakai sewaktu bergerak dari satu tempat ke tempat lainnya di air, bisa untuk mencari ikan, mandi, atau melakukan olahraga air. Prasarana olahraga yang berupa bangunan kolam renang dan diperuntukkan bagi olahraga renang dengan ukuran kolam $20 \mathrm{~m} \times 25 \mathrm{~m}$ atau 25 $\mathrm{m} \times 15 \mathrm{~m}$.

b) Senam

Merupakan suatu cabang olahraga yang melibatkan performa gerakan yang membutuhkan kekuatan, kecepatan, dan keserasian gerakan fisik yang teratur. Terdapat berbagai jenis senam, di antaranya senam lantai, senam hamil, senam aerobik, senam pramuka, Senam Kesegaran Jasmani (SKJ), dll. Biasanya di sekolah dasar, guru-guru mengajarkan senam-senam yang mudah dicerna oleh murid-murid, seperti SKJ dan Senam Pramuka. Namun ketika beranjak remaja, banyak orang melakukan senam aerobik, ataupun senam lainnya termasuk meditasi untuk menenangkan diri

c) Fitness

Merupakan olahraga yang dilakukan dalam ruangan tertutup dan didukung oleh tata udara yang baik. Olahraga ini menggunakan alat-alat khusus seperti:

- Latihan beban dengan tangan yang menggunakan alat bernama dumbbell

- Untuk bahu menggunakan alat bernama shoulder press

- Untuk dada menggunakan alat bernama chest press

- Untuk latihan lari menggunakan alat bernama treadmill

- Untuk latihan seperti bersepeda menggunakan alat bernama endurance

d) Panjat Tebing / Wall climbing

Panjat tebing adalah menaiki, memanjat, mendaki sebuah batuan atau tebing menggunakan seluruh anggota tubuh dan mementingkan keselamatan dengan melihat kecacatan batu seperti celah, tonjolan, retakan sebelum memanjat dan menggunakan alat pengaman yang berstandar. 


\section{e) Bowling}

Merupakan jenis olahraga atau permainan yang dimainkan dengan menggelindingkan bola khusus menggunakan satu tangan. Bola bowling akan digelindingkan ke pin yang berjumlah sepuluh buah yang telah disusun menjadi bentuk segitiga jika dilihat dari atas. Prasarana ukuran untuk permainan ini sebesar $30 \mathrm{~m}$ x 3,46 m yang terdiri dari area persiapan dan olahraga.

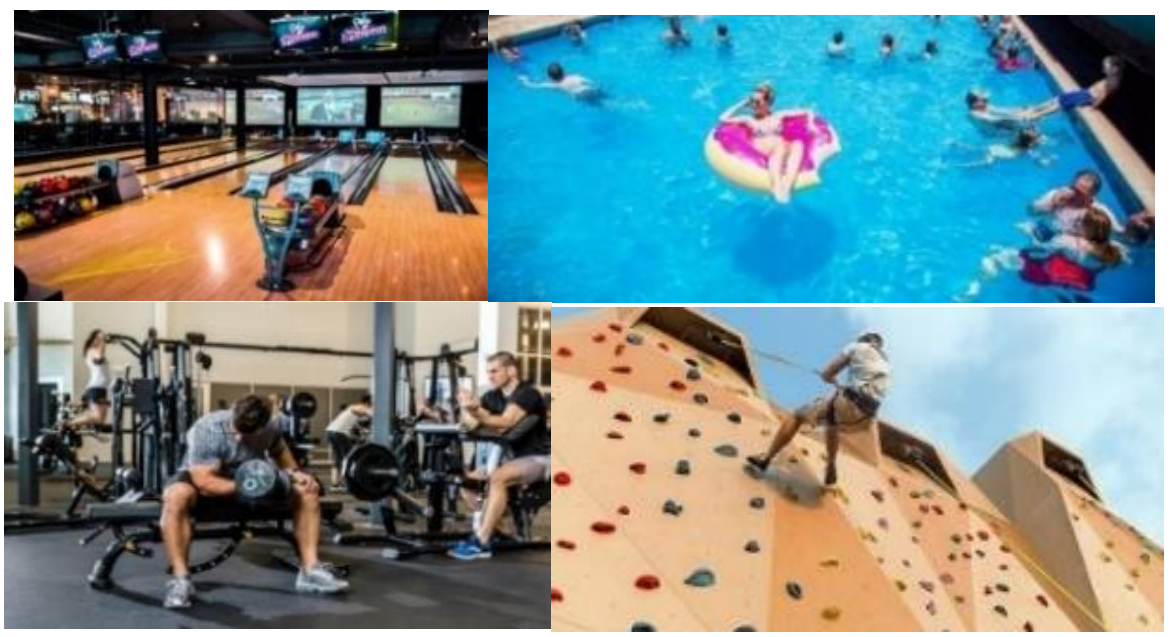

Gambar 2. Jenis-jenis olahraga rekreasi

Sumber: Google, 2019

\section{Peraturan terkait proyek usulan}

a. Undang-undang Nomor 3 Tahun 2005 tentang Sistem Keolahragaan Nasional

b. Peraturan Pemerintah Republik Indonesia Nomor 16 Tahun 2007 tentang Penyelanggaraan Olahraga

c. Peraturan Gubernur DKI Jakarta Nomor 217 Tahun 2014 tentang Organisasi dan Tata Kerja Dinas Olahraga dan Pemuda

\section{METODE PERANCANGAN}

Metode perancangan yang digunakan meliputi tiga tahapan, yaitu: input, analisis dan output. Input berupa data-data yang didapat dari proyek tersebut baik data dari lingkungan tapak maupun dari dalam tapak dan program itu sendiri. Setelah mendapatkan data tersebut, maka tahap selanjutnya adalah menganalisis data tersebut hingga akhirnya mendapatkan sintesis lalu menghasilkan output yaitu hasil akhir.

Metode Perancangan Konvensional

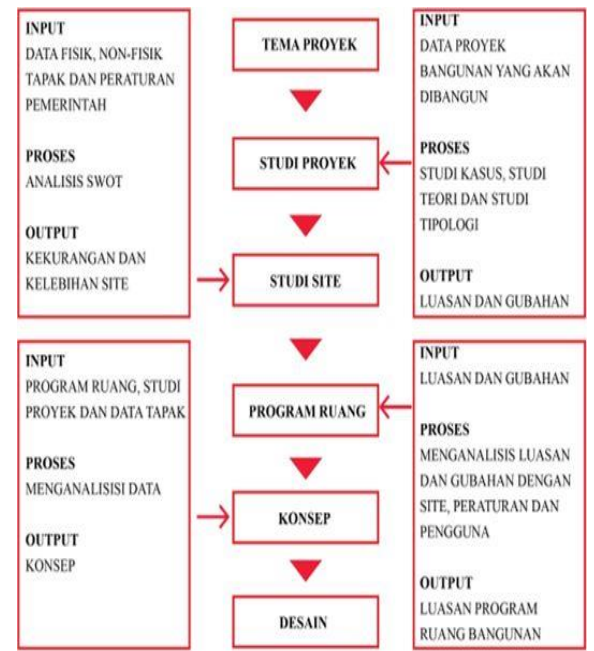

Gambar 3. Metode perancangan Konvensional Sumber: Penulis, 2019 


\section{Metode Perancangan Tipologi}

Pada awalnya bangunan olahraga berawal dari bentuk stadion (Colloseum) pada zaman Yunani yang digunakan untuk fasilitas keagamaan dan sosial, pada masa itu biasanya stadion berbentuk lingkaran atau oval dan tidak beratap atau hanya beratap pada bagian tempat duduk penonton. Pada zaman Romawi dikenal adanya 'Amphitheater' yang dapat dikatakan sebagai pengembangan bangunan stadion dan merupakan penggabungan antara teater dan fasilitas pertandingan. Maka dari itu, telah ada pemikiran penggunaan gedung olahraga untuk kegiatan olahraga dan hiburan (Gaputra, 2019). Seiring kemajuan teknologi, sekitar abad 20 dapat dibuat gedung besar yang seluruhnya beratap yaitu Astrodome, Houston, Texas. Pemanfaatan Gedung olahraga juga berkembang menjadi bangunan serba guna, dengan menyediakan berbagai macam fasilitas penunjang (Gregory, Supardjo, \& Mandey, 2017).

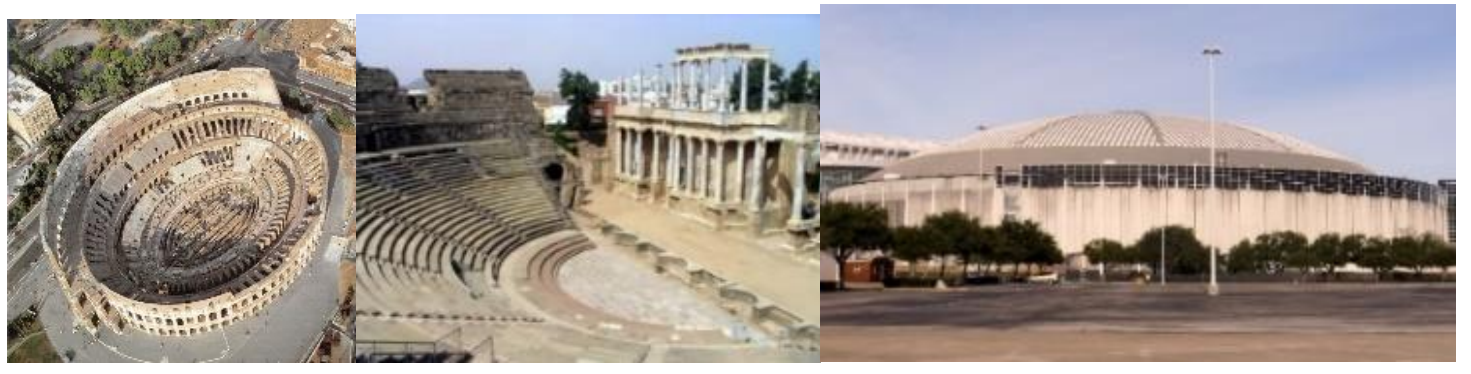

Gambar 4. Perkembangan tipologi gedung olahraga

Sumber: Google, 2019

\section{DISKUSI DAN HASIL}

Klub olahraga di Kawasan Kapuk terletak di Jakarta Barat yang berada di jalan City Boulevard Resort kelurahan Kapuk yang letaknya di antara zona perumahan, dan perkantoran. Klub olahraga dapat diakses dengan transportasi umum tetapi hanya dilewati oleh bus feeder Transjakarta dan dapat diakses dengan jalan kaki karena dekat dengan zona perumahan.

Klub olahraga merupakan suatu wadah bagi masyarakat untuk berolahraga dan berelaksasi dan juga dapat berinteraksi sehingga klub olahraga tidak hanya di pakai oleh satu anggota saja tetapi semua masyarakat dapat menggunakannya. Perencanaan klub olahraga bertujuan agar kawasan Kapuk sendiri memiliki sebuah wadah "Third place" bagi masyarakat sekitar.

Klub olahraga ini memiliki integrasi dengan bangunan lainnya yang di jadikan sebagai plaza terbuka sehingga masyarakat selain melewati integrasi tersebut, masyarakat dapat bersantai dan berinteraksi di dalam plaza tersebut. Plaza tersebut yang menjadikan sebuah wadah third place yang ada di dalam klub olahraga ini.

\section{Pemilihan Lokasi}

Pemilihan lokasi yang dipilih yaitu kawasan Cengkareng, karena jumlah penduduk yang tinggal di Kawasan tersebut terbilang banyak dengan jumlah penduduk sekitar 494.7 ribu jiwa (Badan Pusat Statistik Jakarta Barat, 2014). Kecamatan Cengkareng merupakan kecamatan yang paling banyak dengan jumlah penduduk yang tinggal tetapi akomodasi fasilitas cukup sedikit. Pada pemilihan tapak, lokasi yang terpilih berada pada wilayah kelurahan Kapuk. Wilayah tersebut terpilih karena perkembangan akomodasi transportasi dan juga fasilitas yang cukup sedikit tetapi jumlah penduduk yang tinggal sangat banyak. Kawasan Kapuk juga merupakan wilayah yang banyak akan perkantoran berskala kecil. Tapak dapat di akses oleh feeder Transjakarta yang hanya pemberhentian terdekat yang terletak dengan jarak 200 meter dari tapak. 


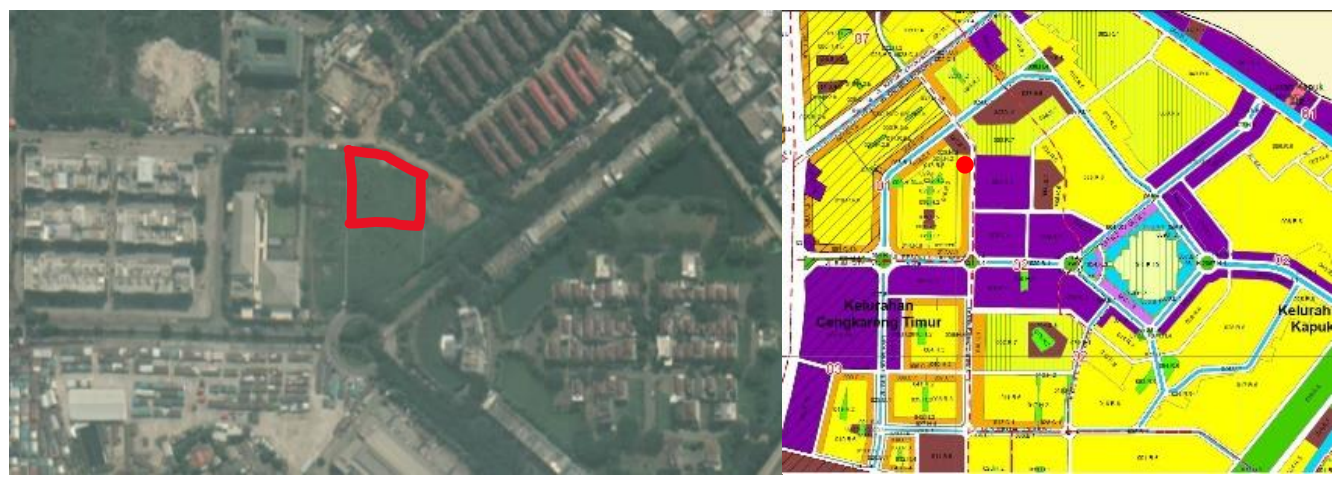

Gambar 5. Lokasi tapak (Jl. City Boulevard Resort, Kapuk, Cengkareng, Jakarta Barat) Sumber: Google Maps dan RDTR Jakarta barat, 2019

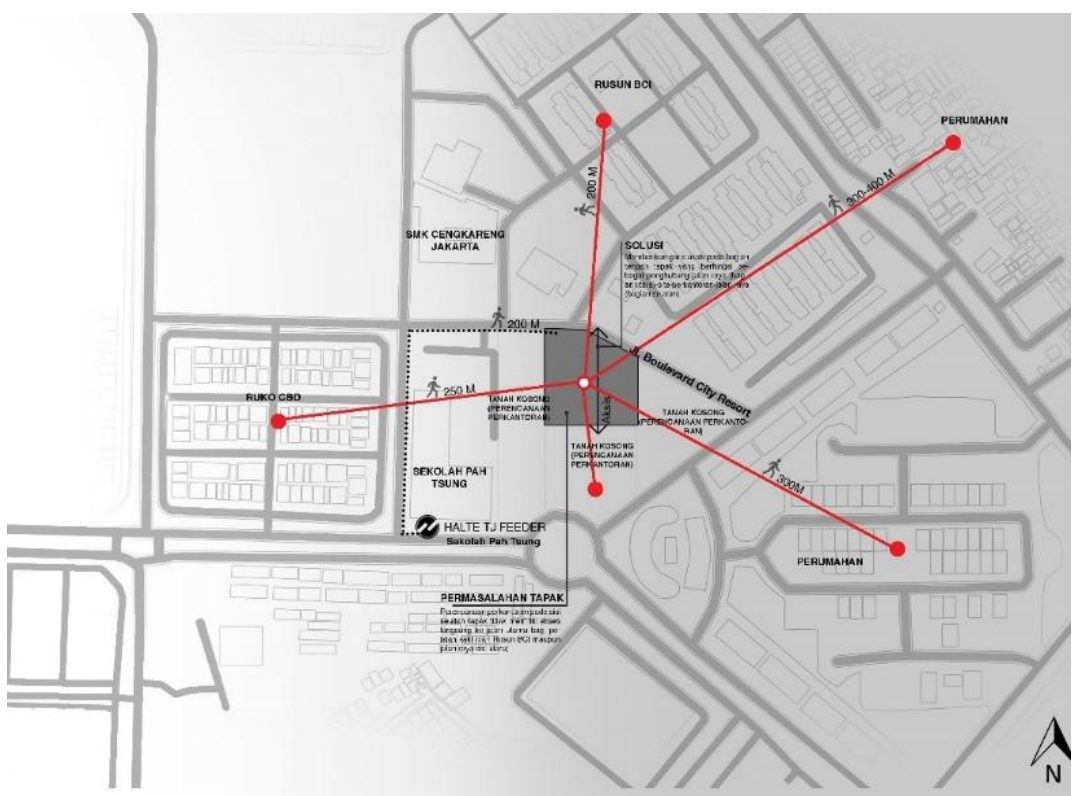

Gambar 6 Jarak pencapaian ke dalam tapak

Sumber: Penulis, 2019

Tapak ini memiliki peraturan zonasi sebagai berikut:

Luas : $5000 \mathrm{~m}^{2}$

KDB $: 50 \% \quad\left(2500 \mathrm{~m}^{2}\right)$

KLB $: 2 \quad\left(10000 \mathrm{~m}^{2}\right)$

$\mathrm{KB}: 4$

$\mathrm{KDH} \quad: 35 \% \quad\left(1750 \mathrm{~m}^{2}\right)$

KTB $: 50 \% \quad\left(2500 \mathrm{~m}^{2}\right)$

Zonasi tapak: K.1 Perkantoran dan Perdagangan jasa

\section{Konsep Desain}

Konsep perancangan didasari dengan pembentukan ruang sesuai dengan fungsi bangunan. Gedung olahraga pada zaman modern bukan lagi hanya sebagai tempat untuk berolahraga saja tetapi bisa digunakan untuk tempat berkumpul atau tempat berinteraksi, dengan demikian, bangunan olahraga bukan lagi sebagai tempat untuk berolahraga saja melainkan juga sebagai wadah interaksi masyarakat. 


\section{Skema Desain}

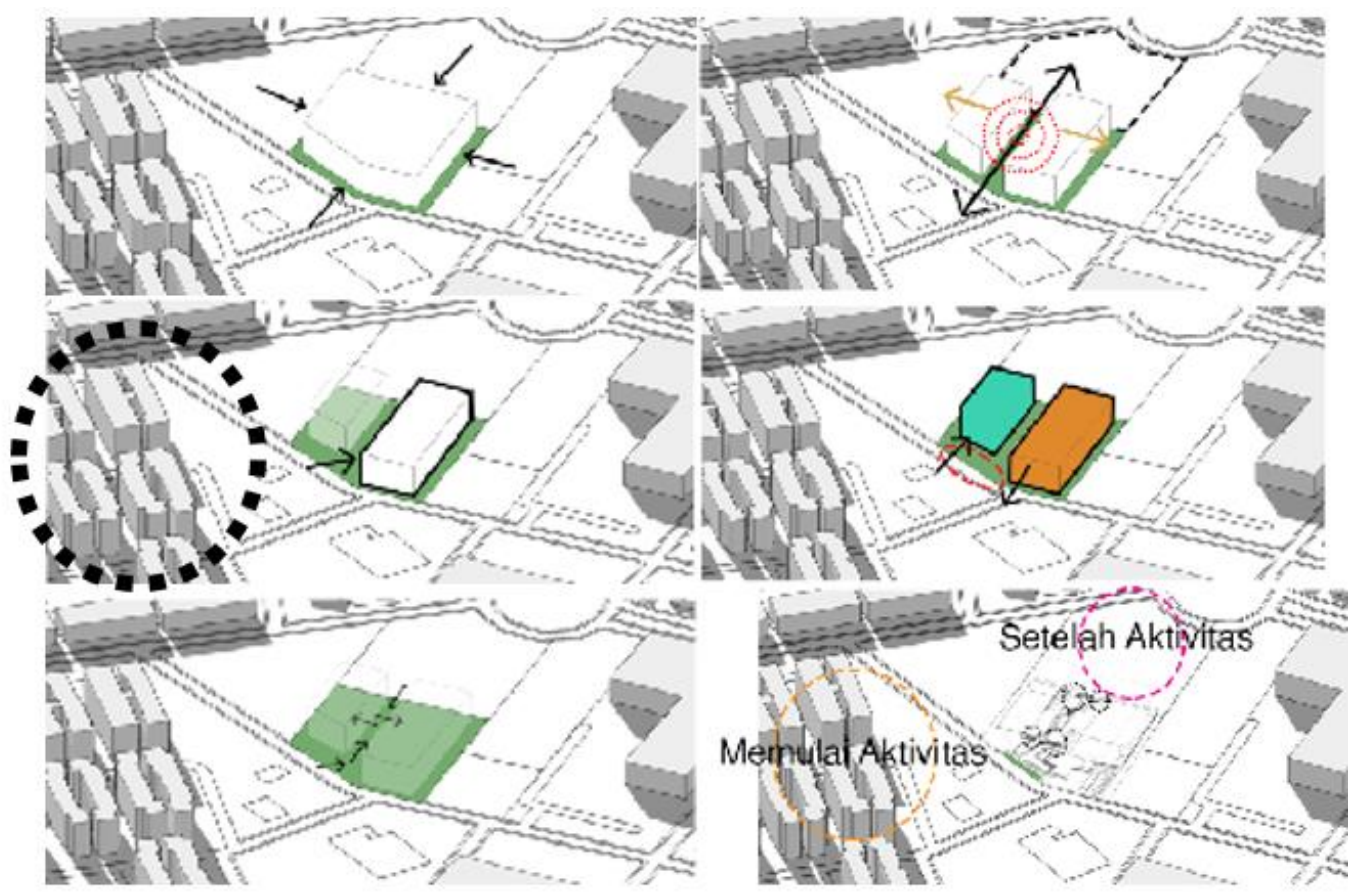

Gambar 7. Proses gubahan massa

Sumber: Penulis, 2019

Pertama, penyesuaian massa dengan ketentuan peraturan kegunaan lahan untuk memaksimalkan fungsionalitas ruang. Bentuk gubahan massa dibentuk menyesuaikan dengan urban fabric eksisting, yaitu pembentukan massa persegi.

Ke dua, pembentukan massa terbelah merupakan respon dari adanya integrasi untuk sirkulasi pejalan kaki dapat mudah menjangkau bangunan lain yang berada pada sisi selatan tapak. Daerah integrasi tersebut dijadikan sebagai plaza terbuka dimana menjadi titik pusat untuk wadah interaksi dan berkumpul dan juga sebagai penghubung 2 massa yang terbelah.

Ke tiga, massa diberikan akses utama, yakni dari jalan City Boulevard Resort. Pintu masuk utama dimiringkan kearah timur laut dikarenakan bukan hanya untuk menghormati aksis jalan City Boulevard Resort tetapi juga untuk menghormati aksis arah view dari rumah susun.

Ke empat, zoning pada bangunan dimasukkan untuk menyesuaikan fungsi ruang dan juga penempatan fungsi bangunan utama yaitu olahraga, diposisikan di sebelah barat (bentuk tapak yang condong kedepan) bertujuan untuk menonjolkan fungsi bangunan utama dan menjadi point of view pada tapak. Sedangkan pada bagian fungsi komersial terdapat setback dan posisi berada pada sisi timur tapak sehingga tidak ada penghalangan pada bangunan fungsi utama (olahraga) yang ingin menjadi point of view pada tapak.

Ke lima, terjadi pembelokan arah sirkulasi di dalam tapak dari sirkulasi utama ke arah plaza. Pembelokan ini bertujuan untuk memberikan suatu pemilihan untuk masyarakat yang datang secara bebas karena fungsi massa pada tapak berkontradiksi.

Ke enam, Pada bagian plaza terdapat besar kecilnya skala pada tangga plaza yang bertujuan sebagai sistem spesifikasi alur sirkulasi pengunjung yang masuk ke dalam tapak. Untuk bagian utara tapak skala tangga pada plaza dibesarkan ke arah bangunan olahraga karena pintu utama pada tapak mengarah ke arah rumah susun yang dianggap sebagai permulaan aktivitas masyarakat sehingga masyarakat dapat berolahraga terlebih dahulu sebelum memulai aktivitas tetapi terdapat pula tangga yang berskala kecil pada bagian bangunan komersial. Untuk bagian selatan tapak terdapat skala tangga yang dibesarkan ke arah bangunan komersial (relaksasi) karena pada bagian selatan pada tapak terdapat perkantoran (perencanaan) yang dianggap setelah melakukan aktivitas bekerja, sehingga masyarakat dapat berelaksasi setelah menjalani aktivitas tetapi terdapat juga tangga yang berskala kecil mengarah pada bangunan olahraga. 


\section{KESIMPULAN}

Untuk menjawab permasalahan the third place dan memberikan wadah untuk masyarakat berkomunitas, maka diusulkan sport club yang juga berfungsi untuk meningkatkan kesehatan dan kebugaran fisik masyarakat yang melakukan aktivitas-aktivitas yang padat serta tempat untuk berkumpul dan berinteraksi sosial bagi masyarakat. Wadah olahraga bukan lagi dipandang sebatas tempat sebagai untuk kebugaran dan kesehatan saja, tetapi sebagai wadah interaksi bagi masyarakat yang menggunakannya sehingga dapat merubah gaya hidup masyarakat yang individualis menjadi terbuka.

Dengan adanya sport club ini, diharapkan bangunan ini dapat menampung masyarakat yang membutuhkan tempat untuk bersantai, berinteraksi, dan berkomunikasi serta menjadi tempat untuk meningkatkan kesadaran akan pentingnya kesehatan dan kebugaran fisik hingga akhirnya tingkat kesadaran berolahraga masyarakat dapat meningkat dan tidak menjadi tertinggal dari negara lain.

Dirancang dengan pendekatan tipologi bangunan olahraga dan perancangan konvensional, sport club ini memiliki peran utama dalam mewadahi aktivitas olahraga, interaksi dan komunikasi antar sesama masyarakat (dewasa hingga anak-anak) agar terjalin suatu konektivitas dan keterbukaan yang dapat membangun solidaritas antar masyarakat dalam peningkatan wadah tempat berkumpul atau third place. Dan juga dengan adanya integrasi antar bangunan di dalam perancangan yang dijadikan sebagai suatu plaza, masyarakat dapat menggunakan sebagai tempat berinteraksi dan juga sebagai aksis penghubung antar bangunan.

\section{REFERENSI}

Akcan, E. (1984). Open Architecture: Migration, Citizenship and the Urban Renewal of BerlinKreuzberg. Basel

Badan Pusat Statistik. Jumlah penduduk DKI Jakarta. Jakarta. Dikutip dari https://www.jakarta.bps.go.id/. 3 Agustus 2019.

Departemen Pekerjaan Umum. (1994). Tata Cara Perencanaan Teknik Bangunan Gedung Olahraga. Bandung: Yayasan LPMB

Gaputra, A. D. (2019). Tipologi Stadion Sepak Bola Kontemporer (Objek Studi Gelora Bandung Lautan Api. Bandung: Institut Teknologi Bandung. Vol. 3, No. 3:244-245.

Gregory, M. A, dkk. (2017). Gelanggang Olahraga Lohoraung di Tagulandang "Folding in Architecture". Manado: UNSRAT. https://media.neliti.com/media/publications/61264-IDnone.pdf. 13 Januari 2020.

Kementerian Pendidikan dan Kebudayaan. (2017). Pendidikan Jasmani, Olahraga, dan Kesehatan. Jakarta: Kemendikbud

Lenny T. T. (2015). DPRD DKI Soroti Kurangnya Sarana dan Prasarana Olahraga. Makalah. Dikutip dari https://www.beritasatu.com/megapolitan/321665/dprd-dki-soroti-kurangnyasarana-dan-prasarana-olahraga. 20 Agustus 2019.

McLaren, D. dan Agyeman, J. (2015). Sharing Cities: A Case for Truly Smart and Sustainable City. Amerika Serikat

Oldenburg, R. (1997). The Great Good Place. Washington DC: Da Capo Press

Utami, S.H. (2018). Hanya 27,6 Persen Masyarakat Indonesia yang Rajin Olahraga. Makalah. Dikutip dari https://www.suara.com/health/2018/10/03/181414/data-hanya-276persen-masyarakat-indonesia-yang-rajin-olahraga. 3 Agustus 2019.

Sturzebecher, P. dan Ulrich, S. (2002). Architecture for Sport: New Concept and International Projects for Sport and Leisure. Inggris: Wiley-Academyi. 
